\title{
Geographic Correlation Between Stomach Cancer Mortality and Food Consumption in Japan
}

\author{
Satoshi Honjo ${ }^{1,3}$, Suminori Kono ${ }^{2}$, Tomio Hirohata ${ }^{1}$, and Shoji Tokunaga ${ }^{1}$
}

\begin{abstract}
We examined the correlation between the prefectural variation of standardized mortality ratio (SMR) for stomach cancer and the consumption of nutrients and food groups using dietary data available for 27 prefectures in Japan. Because data for specific food groups were not available in some prefectures, the number $(n)$ of prefectures analyzed for correlation ranged from 15-27. A three-fold interprefectural variation in SMR for stomach cancer was observed. There was a significant positive correlation between the consumption of salted/dried fishes and SMR $(n=15, r=0.75, p<0.01)$, and vitamin $A$ intake showed a negative correlation $(n=26, r=-0.61$, $p<0.01$ ). Salt consumption did not show a material correlation with SMR $(n=26, r=0.26, p=$ 0.20 ). In the partial correlation analysis $(n=14)$, fruits and yellow-green vegetables showed the inverse associations $(r=-0.43, p=0.19, r=-0.75, p<0.01$, respectively), and pickles and salted/dried fishes showed positive associations $(r=0.53, p=0.09, r=0.67, p=0.02$, respectively) after adjusting for the remaining three variables. The findings suggest that salty foods and vitamin A may be important determinants of the prefectural variation of stomach cancer mortality in Japan.
\end{abstract}

stomach cancer, prefectural nutrition survey, geographic correlation, salted/dried fishes, Vitamin A

Stomach cancer is still a leading cause of cancer deaths in Japan, despite the fact that mortality from this cancer has steadily declined over the past decades $^{11}$. Although previous epidemiological studies are not necessarily consistent in their findings, diet has long been a focus, and several dietary factors have been linked to an increased risk of stomach cancer $^{2-4)}$. It has been strongly suspected that the consumption of fresh fruits and vegetables may be protective against stomach cancer ${ }^{5-14}$, while excessive salt intake or salty food consumption may increase the risk of this cancer ${ }^{5,9,12,14-17)}$.

These hypotheses are also supported by experimental evidence. It has been observed that beta-carotene contained in vegetables has an anti-cancer effect ${ }^{18)}$ and vitamin $C$ contained in fruits and vegetables inhibits the formation of nitroso-compounds that are potent carcinogens ${ }^{19}$. Salt has a promoting effect in chemical carcinogenesis in the stomach of rats $^{20)}$. The in- consistencies in epidemiological studies of individuals have been chiefly ascribed to a limited variation in the habitual diets of individuals within a population ${ }^{21,22)}$.

Evidence from correlation studies is generally considered to be of the least value in causal inference because such studies have limitations due to the socalled ecological fallacy and to contemporaneous measures of exposure and outcome ${ }^{23)}$. Nevertheless, correlation studies have some methodological virtues, in that the range of exposure to the risk is relatively wide between populations and that the effect of measurement error which is inherent in estimating the dietary intakes of individuals can be circumvented by using average values for populations ${ }^{23)}$.

To our knowledge, the geographical distribution of stomach cancer in Japan has not been fully examined in relation to the consumption of nutrients and foods. We collected dietary information for prefectures and examined the relationship between the prefectural

Recieved November 13, 1991; accepted January 16, 1992.

'Department of Public Health, School of Medicine, Kyushu University, 3-1-1 Maidashi, Higashi-ku, Fukuoka, Japan. ${ }^{2}$ Department of Public Health, National Defense Medical College, Tokorozawa, Saitama, Japan. ${ }^{3}$ To whom reprint requests should be sent.

Address for correspondence: Satoshi Honjo, Department of Public Health, School of Medicine, Kyushu University, 3-1-1 Maidashi, Higashi-ku Fukuoka 812, Japan. 
variation in stomach cancer mortality and the consumption of different food groups to test primarily whether the consumption of fruits and yellow-green vegetables is negatively related to stomach cancer and whether the consumption of salt or salty foods is positively associated with this cancer.

\section{MATERIALS AND METHODS}

Dietary data by prefecture were derived from the national nutrition survey (NNS) and prefectural nutrition survey (PNS). The national nutrition survey is carried out annually to report per capita consumption of nutrients and food groups for the entire nation. In this survey, about 300 areas are randomly selected covering all of the 47 prefectures shown in Figure 1. Food intake during three consecutive days in midNovember is recorded by the weighing method on approximately 7000 households ${ }^{24}$. The sample size is often insufficient at the prefectural level. Thus some of the prefectures conduct their own nutrition survey at intervals of several years.

In order to obtain dietary information at the prefectural level, we requested all of the 47 prefectures to provide recent data from PNS. A PNS had not been done in 16 prefectures. Of 31 prefectures having done a PNS, four kept no available dietary data, and one refused to provide the data. Four prefectures of 16 prefectures which had not done a PNS and one prefecture having done a PNS provided the data from the NNS for their prefectures. A total of 31 sets of prefectural data were obtained; 26 based on PNS and 5 on NNS. PNSs were not necessarily uniform in survey method, and three data sets based on PNS and one set on NNS were excluded from the analysis because 1) the number of the subjects was not available, 2) measurement of food intake in households was not done by the weighing method over 3 consecutive days, or 3) per capita intake was not estimated. Data for specific nutrients and food groups were not available in some

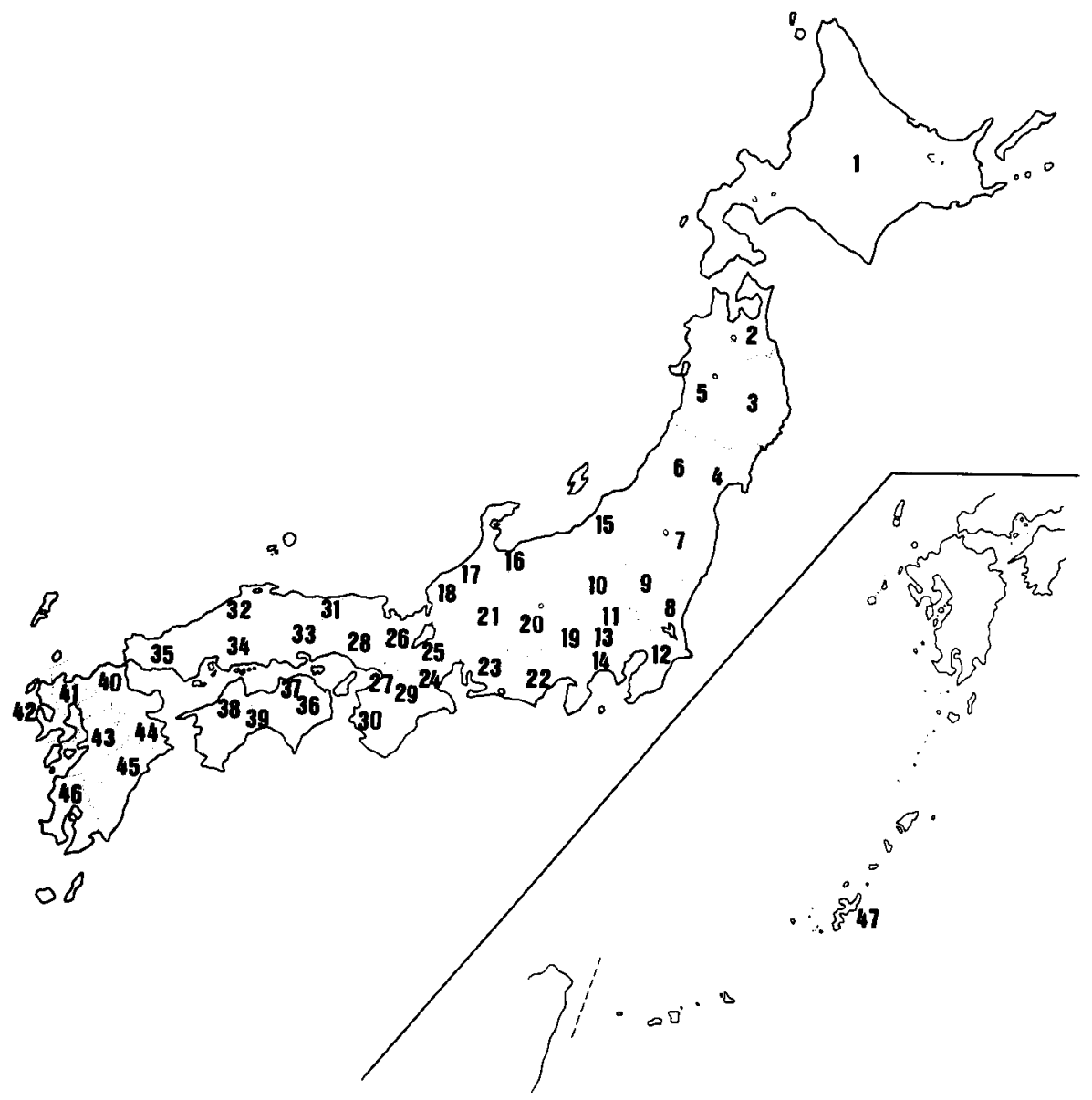

Figure 1. 47 prefectures in Japan. The numbers are the same as in Table 2. 
Table 1. Method of nutrition surveys for prefectural data used for the analysis.

\begin{tabular}{|c|c|c|c|c|c|c|c|c|}
\hline \multirow{2}{*}{\multicolumn{2}{|c|}{ Prefecture }} & \multirow{3}{*}{$\begin{array}{c}\begin{array}{c}\text { Survey } \\
\text { year }\end{array} \\
1986\end{array}$} & \multirow{3}{*}{$\begin{array}{c}\begin{array}{l}\text { Number of } \\
\text { households }\end{array} \\
426\end{array}$} & \multicolumn{3}{|c|}{ Number of subjects } & \multicolumn{2}{|c|}{ Mean age } \\
\hline & & & & \multirow{2}{*}{$\begin{array}{c}\text { Male } \\
801\end{array}$} & \multirow{2}{*}{$\begin{array}{c}\text { Female } \\
929\end{array}$} & \multirow{2}{*}{$\frac{\text { Total }}{1730}$} & \multirow{2}{*}{$\begin{array}{c}\text { Male } \\
35.0\end{array}$} & \multirow{2}{*}{$\frac{\text { Female }}{39.8}$} \\
\hline 2 & Aomori & & & & & & & \\
\hline 3 & Iwate & 1984 & 447 & 783 & 890 & 1673 & 38.0 & 39.3 \\
\hline 4 & Miyagif & 1987 & 60 & 124 & 136 & 260 & 37.5 & 39.1 \\
\hline 5 & Akita & 1987 & 360 & 571 & 683 & 1254 & 39.0 & 43.4 \\
\hline 6 & Yamagata & 1987 & 490 & 924 & 1051 & 1975 & 38.7 & 43.6 \\
\hline 9 & Tochigi & 1986 & 486 & \multicolumn{2}{|c|}{ NA } & 1809 & \multicolumn{2}{|c|}{ NA } \\
\hline 10 & Gunma & 1985 & 320 & \multicolumn{2}{|c|}{ NA } & 1343 & \multicolumn{2}{|c|}{ NA } \\
\hline 11 & Saitama & 1986 & 221 & \multicolumn{2}{|c|}{ NA } & 819 & \multicolumn{2}{|c|}{ NA } \\
\hline 12 & Chiba & 1983 & 414 & \multicolumn{2}{|c|}{ NA } & NA & \multicolumn{2}{|c|}{ NA } \\
\hline 13 & Tokyof & 1988 & 562 & 762 & 844 & 1606 & 36.7 & 37.2 \\
\hline 15 & Niigata & 1986 & 633 & \multicolumn{2}{|c|}{ NA } & 2626 & \multicolumn{2}{|c|}{ NA } \\
\hline 16 & Toyama & 1987 & 267 & 515 & 592 & 1107 & 38.1 & 40.2 \\
\hline 17 & Ishikawa & 1987 & 182 & 367 & 376 & 743 & 37.9 & 40.6 \\
\hline 19 & Yamanashi & 1984 & 494 & 799 & 874 & 1673 & 38.1 & 40.0 \\
\hline 24 & Mie & 1987 & 228 & 392 & 448 & 840 & 38.8 & 42.2 \\
\hline 25 & Shiga & 1986 & 4019 & \multicolumn{2}{|c|}{ NA } & NA & 40.3 & 39.7 \\
\hline 26 & Kyoto & 1983 & 404 & 748 & 775 & 1523 & 36.7 & 41.6 \\
\hline 27 & Osaka & 1987 & 322 & 532 & 546 & 1078 & 35.1 & 37.3 \\
\hline 31 & Tottori & 1987 & 270 & 498 & 574 & 1072 & 39.6 & 41.9 \\
\hline 35 & Yamaguchi & 1985 & 720 & 1062 & 1299 & 2361 & 39.3 & 40.6 \\
\hline 38 & Ehime & 1984 & 557 & 825 & 955 & 1780 & 38.4 & 40.2 \\
\hline 41 & Saga & 1984 & 382 & 797 & 854 & 1651 & 36.3 & 39.9 \\
\hline 42 & Nagasaki & $1983-5 \#$ & 1225 & 2020 & 2352 & 4372 & 34.8 & 38.1 \\
\hline 44 & Oita & 1981 & 565 & 950 & 1037 & 1987 & 36.2 & 37.9 \\
\hline 45 & Miyazakif & 1987 & NA & \multicolumn{2}{|c|}{ NA } & 134 & \multicolumn{2}{|c|}{ NA } \\
\hline 46 & Kagoshima & 1984 & 225 & 304 & 353 & 657 & 38.0 & 41.4 \\
\hline 47 & Okinawa & 1982 & 330 & 579 & 633 & 1212 & 29.0 & 31.8 \\
\hline
\end{tabular}

NA: not available.

$\dagger$ The number added to each prefecture is the same as given in Table 2 .

$¥$ Based on the national nutrition survey.

\# Based on the data summarized for three consecutive years.

of the prefectures, and the number of prefectures used in the analysis was not uniform for all of the nutrients and food groups. The surveys of 24 prefectures were done in November and those of the remaining three prefectures were done between mid-September and mid-December. The data were presented as per capita intake for all ages excluding babies younger than one year, and were not available for males and females separately except for one prefecture. Details of prefectural data sets are summarized in Table 1.

Mortality data for stomach cancer by prefecture was obtained from published statistics. Standardized mortality ratio (SMR) combining males and females in the year 1985 was used as an index of the risk of stomach cancer in the prefectures. Expected number of deaths from stomach cancer in each prefecture was obtained by applying the age-specific death rate of stomach cancer for all of Japan in $1985^{11}$ to the corresponding populations of each prefecture in $1985^{25}$.
The ratio of observed deaths in 1985 to the expected number was multiplied by 100 , and the $95 \%$ confidence interval of the SMR was computed on the assumption that the occurrence of observed death follows a Poisson distribution ${ }^{26)}$. Since the nutritional data were combined for males and females and a highly close correlation between SMRs for each sex (Pearson correlation coefficient $=0.81, p<0.001$ ) was observed, every statistical analysis was combined for both sexes.

The relationships between stomach cancer risk and the consumption of nutrients and food groups were examined by Pearson correlation coefficients. Partial correlation coefficients were also calculated to determine which factor or factors were independently related to mortality from stomach cancer.

\section{RESULTS}

SMRs for stomach cancer for the 47 prefectures are 
Table 2. SMR for stomach cancer in 1985.

\begin{tabular}{|c|c|c|c|}
\hline & Perfecture & SMR & $95 \%$ C.I. \\
\hline 1 & Hokkaido & 97.0 & $92.9-101.2$ \\
\hline 2 & Aomori & 110.0 & $102.1-118.6$ \\
\hline 3 & Iwate & 81.2 & $74.6-88.5$ \\
\hline 4 & Miyagi & 99.1 & $92.6-106.1$ \\
\hline 5 & Akita & 113.8 & $105.5-122.6$ \\
\hline 6 & Yamagata & 120.9 & $112.6-129.8$ \\
\hline 7 & Fukushima & 109.9 & $103.4-116.8$ \\
\hline 8 & Ibaragi & 108.1 & $102.0-114.5$ \\
\hline 9 & Tochigi & 115.6 & $108.1-123.5$ \\
\hline 10 & Gunma & 103.8 & $97.0-111.0$ \\
\hline 11 & Saitama & 104.6 & $100.0-109.4$ \\
\hline 12 & Chiba & 102.2 & $97.5-107.1$ \\
\hline 13 & Tokyo & 99.6 & $96.7-102.6$ \\
\hline 14 & Kanagawa & 98.6 & $94.7-102.7$ \\
\hline 15 & Niigata & 126.6 & $120.3-133.1$ \\
\hline 16 & Toyama & 124.6 & $115.5-134.5$ \\
\hline 17 & Ishikawa & 107.8 & $99.6-117.2$ \\
\hline 18 & Fukui & 95.3 & $86.0-105.6$ \\
\hline 19 & Yamanashi & 95.7 & $86.5-105.9$ \\
\hline 20 & Nagano & 97.3 & $91.6-103.4$ \\
\hline 21 & Gifu & 95.7 & $89.4-102.6$ \\
\hline 22 & Shizuoka & 86.3 & 81.6- 91.2 \\
\hline 23 & Aichi & 96.4 & $92.4-100.6$ \\
\hline 24 & Mie & 96.0 & $89.4-103.0$ \\
\hline 25 & Shiga & 103.4 & $94.6-113.0$ \\
\hline 26 & Kyoto & 99.1 & $93.4-105.2$ \\
\hline 27 & Osaka & 108.7 & $105.0-112.5$ \\
\hline 28 & Hyogo & 97.8 & $93.7-102.1$ \\
\hline 29 & Nara & 117.7 & $108.7-127.5$ \\
\hline 30 & Wakayama & 113.8 & $105.1-123.3$ \\
\hline 31 & Tottori & 102.9 & $92.2-114.9$ \\
\hline 32 & Shimane & 93.7 & $85.1-103.2$ \\
\hline 33 & Okayama & 84.8 & $79.1-90.9$ \\
\hline 34 & Hiroshima & 94.3 & $89.0-99.9$ \\
\hline 35 & Yamaguchi & 92.4 & $85.9-99.3$ \\
\hline 36 & Tokushima & 88.5 & 79.9- 98.1 \\
\hline 37 & Kagawa & 100.9 & $92.4-110.1$ \\
\hline 38 & Ehime & 95.1 & $88.4-102.4$ \\
\hline 39 & Kochi & 90.6 & $82.1-99.8$ \\
\hline 40 & Fukuoka & 95.5 & $91.2-99.9$ \\
\hline 41 & Saga & 98.6 & $89.5-108.5$ \\
\hline 42 & Nagasaki & 100.0 & $93.0-107.5$ \\
\hline 43 & Kumamoto & 76.3 & $70.8-82.2$ \\
\hline 44 & Oita & 85.3 & $78.3-93.0$ \\
\hline 45 & Miyazaki & 85.6 & $78.0-93.9$ \\
\hline 46 & Kagoshima & 69.8 & $64.7-75.4$ \\
\hline 47 & Okinawa & 44.1 & $38.0-51.2$ \\
\hline
\end{tabular}

C.I. : confidence interval. shown in Table 2. In general, prefectures in the northern part of Japan showed high SMRs (prefectures 2, $5-9,11,15,16$ ) except for Iwate (3). Prefectures 27, 29, 30 also had high SMRs. Shizuoka (22) and prefectures in western Japan (prefectures 33-36, 39) showed low SMRs, and Okinawa (47) had the lowest SMR. A three-fold difference was noted between the highest and the lowest SMR.

Simple correlations between SMRs of stomach cancer and per capita daily intake of nutrients and food groups are presented in Tables 3 and 4 . Although data for retinol and beta-carotene were not available separately, vitamin A intake showed a strong negative correlation with SMRs of stomach cancer $(p=0.001)$. None of the other nutrients studied showed an apparent correlation with mortality from stomach cancer.

Among food groups, strong positive associations were observed for the consumption of potatoes, mushrooms, and fish, especially salted/dried fishes. On the contrary, the consumption of meat and its products was found to be negatively associated with stomach cancer mortality. Yellow-green vegetables and dairy products showed a tendency of negative association, while pickles tended to be positively associated.

Okinawa had the lowest SMR for stomach cancer, and the observed correlations seemed to be very dependent on the extreme values for this prefecture, when each scattergram was inspected. Not all of the relevant figures are presented, but this was most likely in the cases of vitamin A and salted/dried fishes as shown in Figures 2 and 3. When Okinawa was excluded, the correlation generally became much weaker, as shown in Table 5. Yet the correlation for salted/dried fishes remained strong.

We further examined the correlation between stomach cancer and the consumption of nutrients and food groups in the prefectures which data are displayed in Figure 3. The seven significant correlations noted in Tables 3 and 4 remained significant, but the correlation was more prominent for the consumption of vitamin A $(r=-0.76, \quad p<0.01)$, yellow-green vegetables $(r=$ $-0.63, p<0.05)$, pickles $(r=0.57, p<0.05)$ and seaweeds $(r=0.54, p<0.05)$. Table 6 presents simple and partial correlation coefficients in 13-15 prefectures which had data on salty foods. Significant simple correlations became much weaker except for yellowgreen vegetables after adjustment for salty foods. Table 7 also presents partial correlation coefficients for the consumption for the four food groups in 14 prefectures which had data on salty foods, fruits, and yellow-green vegetables. 
Table 3. Simple correlation between SMRs for stomach cancer and per capita daily intake of selected nutrients.

\begin{tabular}{lcrrr}
\hline \multirow{2}{*}{ Nutrients (unit) } & Number of & \multicolumn{2}{c}{ Mutrient intake } & \multirow{2}{*}{$\begin{array}{c}\text { Correlation } \\
\text { coefficients }\end{array}$} \\
\cline { 3 - 4 } & prefectures & Mean & Range & \\
\hline Total energy (kcal) & 27 & 2109 & $1880-2304$ & 0.14 \\
Protein (g) & 27 & 81 & $71-88$ & 0.14 \\
Animal protein (g) & 23 & 41 & $34-45$ & 0.01 \\
Fat (g) & 27 & 55 & $45-63$ & -0.32 \\
Carbohydrate (g) & 25 & 304 & $247-343$ & 0.27 \\
Calcium (mg) & 26 & 571 & $514-644$ & -0.02 \\
Iron (mg) & 26 & 11.5 & $9.8-13.5$ & -0.07 \\
Vitamin A (IU) & 26 & 2497 & $1725-3787$ & $-0.6 I^{* *}$ \\
B1 (mg) & 26 & 1.3 & $1.0-1.8$ & 0.12 \\
B2 (mg) C (mg) & 26 & 1.3 & $1.1-1.4$ & -0.13 \\
Salt (g) & 26 & 137 & $100-176$ & 0.03 \\
\% energy from cereals & 26 & 13.3 & $10.3-15.7$ & 0.26 \\
\% animal protein to & 21 & 47 & $41-59$ & -0.02 \\
total protein & 23 & 50 & $45-54$ & -0.26 \\
\hline
\end{tabular}

** $\mathrm{p}<0.01$

Table 4. Simple correlation between SMRs for stomach cancer and per capita daily intake of food groups.

\begin{tabular}{|c|c|c|c|c|}
\hline \multirow{2}{*}{ Food groups (unit) } & \multirow{2}{*}{$\begin{array}{l}\text { Number of } \\
\text { prefectures }\end{array}$} & \multicolumn{2}{|c|}{ Food intake } & \multirow{2}{*}{$\begin{array}{l}\text { Correlation } \\
\text { coefficients }\end{array}$} \\
\hline & & Mean & Range & \\
\hline Cereals (g) & 19 & 295 & $253-327$ & 0.06 \\
\hline Rice $(g)$ & 22 & 227 & $162-277$ & 0.09 \\
\hline Wheat $(g)$ & 22 & 70 & $48-112$ & -0.01 \\
\hline Nuts $(g)$ & 21 & 2.5 & $0.8-6.3$ & 0.17 \\
\hline Potatoes (g) & 26 & 65 & $40-91$ & $0.47^{*}$ \\
\hline Sugar $(g)$ & 23 & 11 & $6-15$ & 0.02 \\
\hline Sweets $(\mathrm{g})$ & 23 & 24 & $14-33$ & 0.39 \\
\hline Oils $(\mathrm{g})$ & 26 & 15 & $8-20$ & -0.35 \\
\hline Beans and its products ( $g$ ) & 25 & 78 & $52-106$ & -0.36 \\
\hline Fruits $(g)$ & 26 & 152 & $110-212$ & 0.03 \\
\hline Yellow-green vegetables $(\mathrm{g})$ & 26 & 73 & $47-109$ & -0.37 \\
\hline Other vegetables $(\mathrm{g})$ & 18 & 167 & $133-204$ & 0.25 \\
\hline Pickles (g) & 19 & 29 & $6-56$ & 0.40 \\
\hline Mushrooms (g) & 19 & 10 & $2-18$ & $0.60^{* *}$ \\
\hline Seaweeds (g) & 25 & 7 & $3-20$ & 0.29 \\
\hline Fish $(\mathrm{g})$ & 26 & 101 & $64-136$ & $0.51^{* *}$ \\
\hline Fresh fishes $(\mathrm{g})$ & 16 & 65 & $46-82$ & 0.44 \\
\hline Fish excluding fresh fishes $(\mathrm{g})$ & 17 & 35 & $18-57$ & $0.50^{*}$ \\
\hline Salted/dried fishes $(\mathrm{g})$ & 15 & 16 & $5-26$ & $0.75^{* *}$ \\
\hline Meat and its products (g) & 27 & 66 & $44-94$ & $-0.54^{* *}$ \\
\hline Eggs $(g)$ & 27 & 41 & $32-50$ & -0.21 \\
\hline Dairy products $(\mathrm{g})$ & 27 & 103 & $66-140$ & -0.28 \\
\hline Milk (g) & 19 & 97 & $69-123$ & -0.32 \\
\hline
\end{tabular}

${ }^{* *} \mathrm{p}<0.01,{ }^{*} \mathrm{p}<0.05$ 


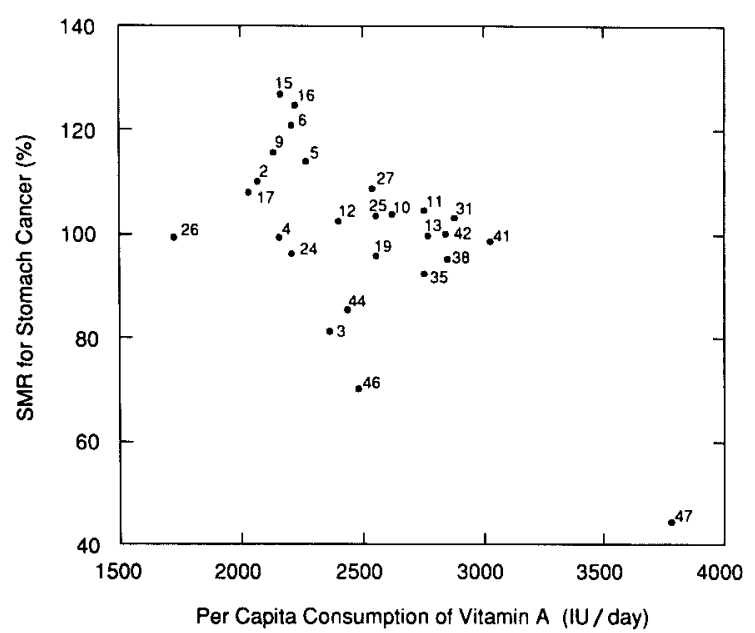

Figure 2. Stomach cancer risk within Japan in association with the consumption of vitamin A. Attached numbers correspond to the prefectures in Table 2 and Figure 1.

Table 5. Simple correlation between SMRs for stomach cancer and per capita intake of selected nutrients and food groups in the analysis excluding Okinawa.

\begin{tabular}{lcc}
\hline Nutrients and food items & $\begin{array}{c}\text { Number of } \\
\text { prefectures }\end{array}$ & $\begin{array}{c}\text { Correlation } \\
\text { coefficients }\end{array}$ \\
\hline Vitamin A & 25 & -0.31 \\
Potatoes & 25 & 0.23 \\
Yellow-green vegetable & 25 & -0.29 \\
Pickles & 18 & 0.19 \\
Mushrooms & 18 & 0.44 \\
Salted/dried fishes & 14 & $0.60^{*}$ \\
Meat and its products & 26 & -0.35 \\
Dairy products & 26 & -0.23 \\
\hline
\end{tabular}

* $\mathrm{p}<0.05$

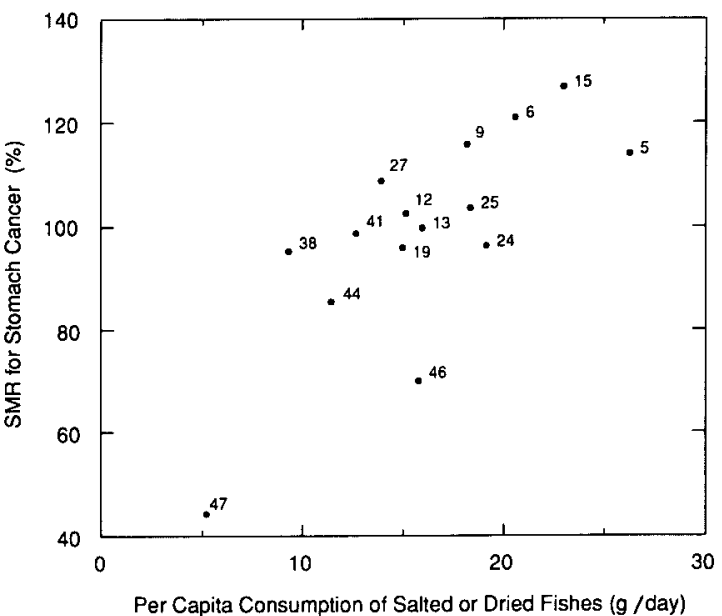

Figure 3. Stomach cancer risk within Japan in association with the consumption of salted/dried fishes. Attached numbers correspond to the prefectures in Table 2 and Figure 1.

Table 7. Partial correlation between SMRs for stomach cancer and per capita intake of selected food groups in the 14 prefectures used in Table 6.

\begin{tabular}{lc}
\hline \multicolumn{1}{c}{ Food groups } & $\begin{array}{c}\text { Partial cerrelation } \\
\text { coefficients (p value) }\end{array}$ \\
\hline Fruits & $-0.43(0.19)$ \\
Yellow-green vegetables & $-0.75(<0.01)$ \\
Pickles & $0.53(0.09)$ \\
Salted/dried fishes & $0.67(0.02)$ \\
\hline
\end{tabular}

For each analysis other three variables were adjusted.

Table 6. Simple and partial correlation between SMRs for stomach cancer and per capita intake of selected nutrients and food groups in the $13-15$ prefectures.

\begin{tabular}{|c|c|c|c|}
\hline \multirow{2}{*}{ Nutrients and food groups } & \multicolumn{3}{|c|}{ Correlation coefficients } \\
\hline & Simple & Partial† & Partialt \\
\hline Cereals & 0.07 (14)\# & $0.19(14)$ & $0.07(14)$ \\
\hline Potatoes & $0.61^{*}(15)$ & $0.26(15)$ & $0.04(14)$ \\
\hline Fruits & $0.11 \quad(15)$ & $0.03(15)$ & $-0.21(14)$ \\
\hline Yellow-green vegetables & $-0.63^{*}(15)$ & $-0.70^{*}(15)$ & $-0.69 *(14)$ \\
\hline Pickles & $0.57 *(14)$ & $0.31(14)$ & - \\
\hline Mushrooms & $0.72 * *(13)$ & 0.27 (13) & $0.07(13)$ \\
\hline Meat and its products & $-0.78^{* *}(15)$ & $-0.47(15)$ & $-0.43(14)$ \\
\hline Dairy products & $-0.31 \quad(15)$ & $-0.06(15)$ & $0.01(14)$ \\
\hline
\end{tabular}

** $\mathrm{p}<0.01, * \mathrm{p}<0.05$

$\dagger$ Adjusting for salted/dried fishes.

$\ddagger$ Adjusting for salted/dried fishes and pickles.

\# The number of prefectures available are shown in parentheses. 


\section{DISCUSSION}

The present study could not examine dietary data for all of the 47 prefectures in Japan. A total of 20 prefectures had to be excluded because dietary data were unavailable. This may mitigate the value of the present findings, but it should be noted that there was no intentional selection of prefectures. Further, prefectures excluded in the analysis were not those with extremely high or low risks of stomach cancer. It should be cautioned in interpreting the data for some food groups which showed some different correlations in different data sets (18-27 prefectures and 13-15 prefectures which both included Okinawa). However, on the whole correlation coefficients of 8 selected food items in Table 6 based on 13-15 prefectures were basically comparable with those computed on the basis of 18-27 prefectures. The mean age of subjects in Okinawa was the youngest and the consumption of salty foods (salted/dried fishes and pickles) in this prefecture was the lowest. The positive association between salted/dried fishes and stomach cancer remained after excluding Okinawa from the analysis.

It is well known that a considerable time lapse is needed between exposure to carcinogenic agents and the development of cancer. Therefore, it may be desirable to compare prefectural dietary habits recorded a few decades earlier with recent geographical distribution of stomach cancer. Fortunately, geographical distribution of stomach cancer in Japan has been very stable over years. For example, 1985 prefectural SMRs for stomach cancer correspond very well to those in 1965 and geographical correlation coefficient reached $0.86(p \fallingdotseq 0.0001)^{27,28)}$. Our ecological study is probably valid because we can reasonably expect similar geographical distribution of stomach cancer in the future. Besides, descriptions of dietary habits by prefecture in old days seem to well reflect the current dietary habits ${ }^{29}$. If dietary habits are related to not only "initiation," but also to "promotion," relatively short time lapse would be required.

The present findings are generally in agreement with the current hypothesis that salty food consumption may increase the risk of the stomach cancer and vita$\min A$ may be protective against it. While total salt intake did not show an apparent association, the consumption of salty foods such as salted/dried fishes and pickles was positively related to prefectural variations of stomach cancer mortality. The lack of association with total salt intake strongly suggests that intake of foods with high salt concentration is important in the development of stomach cancer. A previous correlation study based on a broader geographic unit also failed to find an association between total salt consumption and stomach cancer mortality in $\mathrm{Japan}^{30}$, while an earlier study observed a fairly strong correlation between salt concentration in malted beans and stomach cancer mortality in 18 prefectures ${ }^{31)}$. Thus it is not surprising that a case-control study of stomach cancer measuring total salt intake from a large number of foods did not observe the association ${ }^{32)}$, while some studies focusing on a limited number of salty foods found an association ${ }^{5,9,12,14,16,17)}$.

Yellow-green vegetables showed a strong inverse relation with stomach cancer mortality in the analysis of 15 prefectures, although the correlation in 27 prefectures was not striking. The negative correlation with fruits was not apparent in analyses of both 27 and 15 prefectures. Vitamin A intake showed a strong negative correlation whether the analysis was done in the 27 or 15 prefectures. Thus the present findings corroborate the hypothesis of vitamin $\mathrm{A}$ and stomach cancer.

The positive association of the consumption of potatoes was consistent with the result of some casecontrol studies ${ }^{16,33)}$. Another case-control study in Israel revealed that the patients had a higher consumption of starchy foods ${ }^{34}$. Cereals or cereal products were also shown to increase the risk of stomach cancer in some previous analytical studies, ${ }^{7,9,12,14,32)}$. A correlation study of 16 countries also found a striking association between cereal consumption and stomach cancer $(r=0.75)$ and in that study Japan was second in the per capita consumption among those 16 countries $^{35)}$. The range of cereal consumption was about five-fold in that study. The present study failed to show an association with either cereals or rice consumption. The limited prefectural variation in the consumption of cereals and rice in this study was not expected to be associated with differences in cancer mortality in a country which has a high mortality from stomach cancer and which consumes a large quantity of rice. Regarding the positive relation between mushrooms and stomach cancer, the intake of mushrooms was closely correlated with that of salted/dried fishes $(r=0.89)$, and the partial correlation became insignificant $(r=0.27, p=0.39)$ after controlling for salted/dried fishes.

The negative association between the consumption of meat and stomach cancer may also be secondary to other factors. Meat consumption was negatively correlated with the consumption of salted/dried fishes $(r=-0.79)$, and a partial correlation remained $(r=$ $-0.47, p=0.12$ ) after adjustment of salted/dried fishes. A case-control study in Turkey showed the protective effect of meat consumption ${ }^{14}$, and an international correlation study demonstrated an inverse relationship between meat consumption and stomach cancer 
mortality ${ }^{21)}$. Fat intake was negatively associated with stomach cancer mortality in the analysis of 27 prefectures $(p=0.11)$ and was closely related with meat intake $(r=0.55, p<0.01)$. The partial correlation was not significant $(r=-0.32, p=0.26)$ after adjusting for salted/dried fishes $(n=15)$. Japanese get their fat mainly from oils (about $27 \%$ of the total) and meat

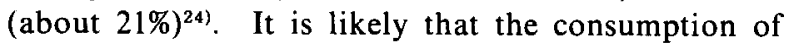
meat or fat reflects certain dietary habits associated with a decreased risk of stomach cancer, for instance, eating less salted/dried fishes, more use of a refrigerator, or a more westernized diet.

In summary, although the present study was based on dietary data of a limited number of prefectures, the findings suggest that the consumption of salty foods and vitamin A may determine the geographic variation of stomach cancer mortality in Japan.

\section{ACKNOWLEDGMENTS}

The authors acknowledge the authorities of each prefecture for providing the data from their nutrition surveys.

\section{REFERENCES}

1. Ministry of health and welfare of Japan, Minister's secretariat, Statistics and Information department. Vital statistics 1985, vol. 1, 3, Koseitokei Kyokai, Tokyo, 1987 (in Japanese).

2. Haenszel W, Kurihara M. Studies of Japanese migrants. I. Mortality from cancer and other diseases among Japanese in the United States. J Natl Cancer Inst, 1968 ; 40: 4368.

3. Muir CS, Malhotra A. Changing patterns of cancer incidence in five continents. In; M Kurihara ed. Changing Cancer Patterns and Topics in Cancer Epidemiology. Gann Monograph on Cancer Research 33, Japan Scientific Societies Press, Tokyo, 1987.

4. Tominaga $\mathrm{S}$. Decreasing trend of stomach cancer in Japan. Jpn J Cancer Res, 1987 ; 78 : 1-10.

5. Haenszel W, Kurihara M, Segi M, Lee RKC. Stomach cancer among Japanese in Hawaii. J Natl Cancer Inst, $1972 ; 49: 969-988$.

6. Haenszel W, Kurihara M, Locke FB, Shimizu K, Segi M. Stomach cancer in Japan. J Natl Cancer Inst, 1976; 56 : 265-278.

7. Bjelke E. Epidemiologic studies of cancer of the stomach, colon, and rectum. Scand J Gastroenterol, 1974;9 (Suppl): 1-235.

8. Correa P, Fontham E, Pickle LW et al. Dietary determinants of gastric cancer in south-Louisiana inhabitants. JNCI, $1985 ; 75: 645-654$.

9. Trichopoulos D, Ouranos G, Day NE et al. Diet and cancer of the stomach: a case-control study in Greece. Int J Cancer, 1985; 36 : 291-297.

10. Jedrychowski W, Wahrendorf J, Popiela T, Rachtan J. A case-control study of dietary factors and stomach cancer risk in Poland. Int $\mathbf{J}$ Cancer, $1986 ; 37 ; 837-842$.

11. Kono S, Ikeda M, Tokudome S, Kuratsune $\mathbf{M}$. A casecontrol study of gastric cancer and diet in northern Kyu- shu, Japan. Jpn J Cancer Res, $1988 ; 79:$ 1067-1074.

12. La Vecchia C, Negri E, Decarli A, D'Avanzo B, Franceschi S. A case-control study of diet and gastric cancer in northern Italy. Int J Cancer, 1987 ; 40: 484-489.

13. You WC, Blot WJ, Chang YS et al. Diet and high risk of stomach cancer in Shandong, China. Cancer Res, 1988; 48: 3518-3523.

14. Demirer T, Icli F, Uzunalimoglu O, Kucuk O. Diet and stomach cancer incidence : a case-control study in Turkey. Cancer, $1990 ; 65: 2344-2348$.

15. Joossens J, Geboers J. Nutrition and gastric cancer. Nutr Cancer, $1981 ; 2: 250-261$.

16. Hu J, Zhang S, Jia E et al. Diet and cancer of the stomach : a case-control study in China. Int J Cancer, 1988; 41: 331-335.

17. Buiatti E, Palli D, Decarli A et al. A case-control study of gastric cancer and diet in Italy. Int J Cancer, 1989; 44: 611-616.

18. Seifter E, Rettura G, Padawer J, Levenson SM. Moloney murine sarcoma virus tumors in $\mathrm{CBA} / \mathrm{J}$ mice: chemopreventive and chemotherapeutic actions of supplemental beta-carotene. JNCI, 1982; 68: 835-840.

19. Mirvish SS. The etiology of gastric cancer : intragastric nitrosamide formation and other theories. JNCI, 1983; $71: 629-647$.

20. Tatematsu M, Takahashi M, Fukushima S, Hananouchi M, Shirai T. Effects in rats of sodium chloride on experimental gastric cancers induced by $\mathrm{N}$-methyl-N'-nitro-Nnitrosoguanidine or 4-nitroquinoline-1-oxide. J Natl Cancer Inst, 1975; $55:$ 101-106.

21. Tominaga S, Ogawa $\mathbf{H}$, Kuroishi T. Usefulness of correlation analysis in the epidemiology of stomach cancer. Natl Cancer Inst Monogr, 1982; 62: 135-140.

22. Goodwin PJ, Boyd NF. Critical appraisal of the evidence that dietary fat intake is related to breast cancer risk in humans. JNCI, 1987; $79: 473-485$.

23. Parkin DM. Cancers of the breast, endometrium and ovary: geographic correlations. Eur $\mathbf{J}$ Cancer Clin Oncol, 1989 ; 25 : 1917-1925.

24. Ministry of health and welfare of Japan, Health service bureau, Health promotion and nutrition division. The present condition of national nutrition in 1985. Daiichishuppan, Tokyo, 1987 (in Japanese).

25. Management and coordination agency of Japan, Statistics bureau. 1985 Population census of Japan, vol. 2, part 1. Nippontokei Kyokai, Tokyo, 1986 (in Japanese).

26. Armitage P, Berry G. (1987). Statistical methods in medical research. Blackwell Scientific Pub, Oxford, 1987.

27. Ministry of health and welfare of Japan, Minister's secretariat, Statistics Division. Vital statistics 1965, vol. 2, Koseitokei Kyokai, Tokyo, 1967 (in Japanese).

28. Office of the Prime Minister of Japan, Bureau of Statistics. 1965 Population census of Japan, vol. 3, part 1. Nippontokei Kyokai, Tokyo, 1967 (in Japanese).

29. Nihon no shokuseikatsu zenshu (Dietary habits in Japan), vol. 1-47. Nosangyoson Bunka Kyokai, Tokyo, 19841991 (in Japanese).

30. Kono S, Ikeda M, Ogata M. Salt and geographical mortality of gastric cancer and stroke in Japan. J Epidemiol Community Health, 1983 ; 37 : 43-46.

31. Hirayama T. A study of epidemiology of stomach cancer, with special reference to the effect of the diet factor. Bull Inst Pub Health, 1963 ; 12 : 85-96.

32. Risch HA, Jain M, Choi NW et al. Dietary factors and the incidence of cancer of the stomach. Am J Epidemiol, 
$1985 ; 122: 947-959$.

33. Graham S, Lilienfeld AM, Tidings JE. Dietary and purgation factors in the epidemiology of gastric cancer. Cancer, $1967 ; 20: 2224-2234$.

34. Modan B, Lubin F, Barell $\mathrm{V}$ et al. The role of starches in the etiology of gastric cancer. Cancer, $1974 ; 34: 2087-$ 2092.

35. Hakama M, Saxén EA. Cereal consumption and gastric cancer. Int J Cancer, $1967 ; 2$ : 265-268. 